\title{
Day of dialogue: Expanding opportunities for increased access to emergency contraception (EC) in Nigeria
}

Population Council

Follow this and additional works at: https://knowledgecommons.popcouncil.org/departments_sbsr-rh

Part of the Demography, Population, and Ecology Commons, Family, Life Course, and Society Commons, International Public Health Commons, and the Women's Health Commons How does access to this work benefit you? Let us know!

\section{Recommended Citation}

Population Council Nigeria. 2013. "Day of dialogue: Expanding opportunities for increased access to emergency contraception (EC) in Nigeria," meeting report. Abuja: Population Council. 


\section{DAY OF DIALOGUE: EXPANDING OPPORTUNITIES FOR INCREASED ACCESS TO EMERGENCY CONTRACEPTION (EC) IN NIGERIA}

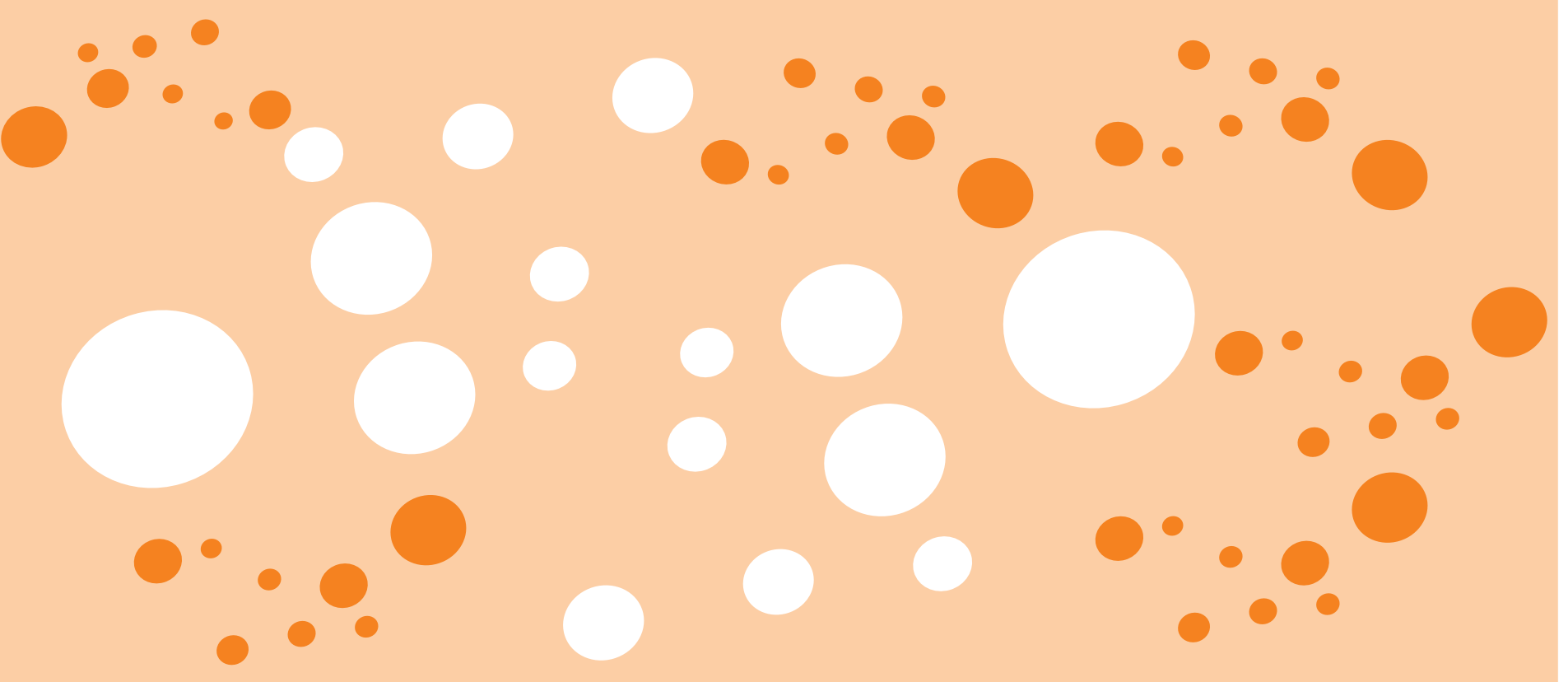

March 5, 2013 


\section{DAY OF DIALOGUE: EXPANDING OPPORTUNITIES FOR INCREASED ACCESS TO EMERGENCY CONTRACEPTION (EC) IN NIGERIA}

Meeting Report March 5, 2013

Population Council Nigeria 


\section{Population Council}

The Population Council confronts critical health and development issues-from stopping the spread of HIV to improving reproductive health and ensuring that young people lead full and productive lives. Through biomedical, social science, and public health research in 50 countries, we work with our partners to deliver solutions that lead to more effective policies, programs, and technologies that improve lives around the world. Established in 1952 and headquartered in New York, the Council is a non governmental, nonprofit organization governed by an international board of trustees.

Population Council

Nigeria

House 4, 16 Mafemi Crescent

Off Solomon Lar Way, Utako District

Abuja

Nigeria

www.popcouncil.org

Suggested citation: Population Council Nigeria. "Day of Dialogue: Expanding opportunities for increased access to emergency contraception (EC) in Nigeria” Meeting Report March 5, 2013. Abuja, Nigeria.

(C) 2013 The Population Council, Inc.

Any part of this publication may be photocopied without permission from the publisher provided that copies are distributed without charge and that full source citation is provided. The Population Council would appreciate receiving a copy of any materials in which the text is used. 


\section{TABLE OF CONTENTS}

List of acronyms

Executive summary

1

Introduction

3

Addressing prevailing misconceptions

Stimulating Demand and Uptake

Scale-up approaches

Strengthening policy support

Next steps

Appendix I

Appendix II

References 


\section{LIST OF ACRONYMS}

BCC

EC

ECPs

EDL

FGN

$\mathrm{FMoH}$

ICEC

INGO

KOLS

NAFDAC

NDHS

NGOs

NMA

NURHI

OTC

OVC

PC

PEls

PMVs

PSN

$\mathrm{RH}$

SFH

SOGON

STIS

UN

UNFPA

WHO
Behavior Change Communication

Emergency Contraception

Emergency Contraceptive Pills

Essential Drugs List

Federal Government of Nigeria

Federal Ministry of Health

International Consortium for Emergency Contraception

International Non-governmental Organization

Key Opinion Leaders

National Agency for Foods, Drugs Administration \& Control

Nigeria Demographic \& Health Survey

Non-Governmental Organizations

Nigeria Medical Association

Nigerian Urban Reproductive Health Initiative

Over The Counter

Orphan and Vulnerable Children

Population Council

Polio Eradication Initiatives

Patent Medicine Vendors

Pharmaceutical Society of Nigeria

Reproductive Health

Society for Family Health

Society of Obstetricians \& Gynecologists of Nigeria

Sexually Transmitted Infections

United Nations

United Nations' Population Fund

World Health Organization 


\section{EXECUTIVE SUMMARY}

Emergency contraception (EC) is an innovation that empowers women to avoid pregnancy following unprotected intercourse. It differs from other conventional methods of family planning in that the intervention occurs after exposure to unprotected intercourse. It is, therefore, appropriate in situations where either no contraceptive method was used, a regular method was missed, contraceptive failure occurred as in condom breakage, or in cases of rape and sexual assault. Appropriate and widespread use of EC can eliminate most cases of unwanted pregnancy and its sequelae such as unsafe abortion and associated maternal morbidity and mortality. Despite the huge potential in EC, its utilization has not been taken to scale in many developing countries, including Nigeria where 11 percent of all births by women aged 15-49 are either unwanted or mistimed, and unmet need for family planning among currently married women is as high as 20.2 percent (NPC and ICF Macro, 2009). Lack of proper knowledge and understanding of EC among service providers in Nigeria as well as insufficient policy support are contributory to its poor uptake.

In order to create a supportive policy and service delivery environment for EC and improve uptake, the Population Council, in 2011, conducted in Nigeria a survey of service providers' knowledge, attitudes and practices regarding EC, supplemented by indepth interviews with 'Key Opinion Leaders' (KOLs) regarding their perceptions. This study revealed gaps that have implications for policy and programming (Ahonsi, et al, 2012). In collaboration with the International Consortium for Emergency Contraception (ICEC), the Council convened a 'Day of Dialogue' on EC to discuss the key research findings and to recommend strategic considerations for repositioning EC within the country's family planning program. The event drew participants from both the public and private sectors, local and international non-governmental organizations, regulatory bodies and donor agencies, United Nations agencies and advocacy organizations. The dialogue yielded broad consensus on a number of critical policy and program/service delivery issues around expansion of access to EC:

- Ensure that the commonly available EC brands in the country such as Postinor-2 and Pregnon are included on Nigeria's Essential Drugs List (EDL);

- Pro-actively deploy family planning community champions to make a case for the expansion of access to EC for all categories of women, following the example of other successful public health initiatives such as the Polio Eradication Initiative (PEI);

- Conduct intensive advocacy using scientific evidence to clear up prevailing misconceptions about EC in Nigeria; 
- Devise means to provide accurate information to service providers, potential clients and policy-makers in highly accessible and culturally-sensitive ways in order to minimize resistance and improve uptake; and

- Leverage opportunities to disseminate current research findings on EC at meetings and conferences of professional bodies such as the Nigeria Medical Association and the Association of Patent Medicine Vendors. 


\section{INTRODUCTION}

Emergency contraceptives (ECs) are relatively new innovations in Nigeria's family planning (FP) strategy. With maternal mortality currently at 545 per 100,000, a modern contraceptive prevalence rate of 10 percent, and with over one-third of Nigeria's 170 million population aged 1024 , there are sufficient reasons to undertake efforts to address the health outlook among the rapidly growing adolescent population. Current evidence suggests that induced abortion, as a result of unwanted pregnancy, accounts for 11 percent of maternal mortality in Nigeria, indicating a high unmet need for contraception, including emergency contraception. Indeed, 11 percent of all births to women of reproductive age in Nigeria are either unwanted or mistimed, and 20.2 percent of currently married women have unmet need for family planning methods to stop or delay childbearing (NPC and ICF Macro, 2009).

Emergency contraceptive pills (ECPs) are highly effective in preventing unwanted pregnancy and are suitable for both married and unmarried women who after unprotected sex wish to avoid pregnancy. In spite of the mounting evidence that ECs are very effective and safe, they are not widely available for use among the vulnerable groups for reasons such as fears about safety and future infertility and concerns that $\mathrm{EC}$ is an abortifacient.

Postinor 10 was the first EC that entered the Nigerian market in the late 1990s, before it was replaced by Postinor 2 on the recommendation of the World Health Organization (WHO) in 2001. These were the only registered ECs in Nigeria until 2007 when the Society for Family Health (SFH) started distribution of Pregnon, a subsidized brand, to expand options to all classes of Nigerians who need EC. Between 1999 and 2013 the uptake of ECPs has grown from 160,000 to at least $2,000,000$ doses per annum despite lack of full public sector engagement. At present, uptake of ECP is less than 1\% (Ahonsi, et al, 2012). There is an absence of full government participation in EC provision, with distribution almost entirely under the control of the largely unregulated private sector. This skewed supply situation is unfavorable for healthy institutionalization of this essential commodity into the country's FP program.

In order to improve the program and policy environment for EC in Nigeria, the Population Council, with funding from the Bill and Melinda Gates Foundation, and through the International Consortium for Emergency Contraception (ICEC) conducted a study in 2011 to document providers' knowledge, attitudes, beliefs and practices regarding EC and to identify key opinion leaders' (KOLs) perspectives and insights pertaining to EC policy and program issues. The findings from this study are described in more detail in a Council-published Research Brief (Ahonsi, et al, 2012). It documents several interesting program and policy-related issues that can be used to guide policies and programs. 
To maximize the utilization of the findings from this study for the improvement of the EC policy and service environment in Nigeria, the Council, in collaboration with the ICEC convened a 'Day of Dialogue' that brought together a broad range of stakeholders from government ministries and agencies, local and international non-governmental organizations, including UNFPA, Nigerian Urban Reproductive Health Initiative, the Patent Medicine Vendors Association, Pathfinder International, Advocacy Nigeria, Education As a Vaccine (a youth-serving NGO), the Family Planning Action Group, and representatives of Society for Family Health (SFH, the single largest supplier of EC to the Nigerian market), Liverpool School of Tropical Medicine, and Association for Reproductive and Family Health. This report presents the highlights of this dialogue.

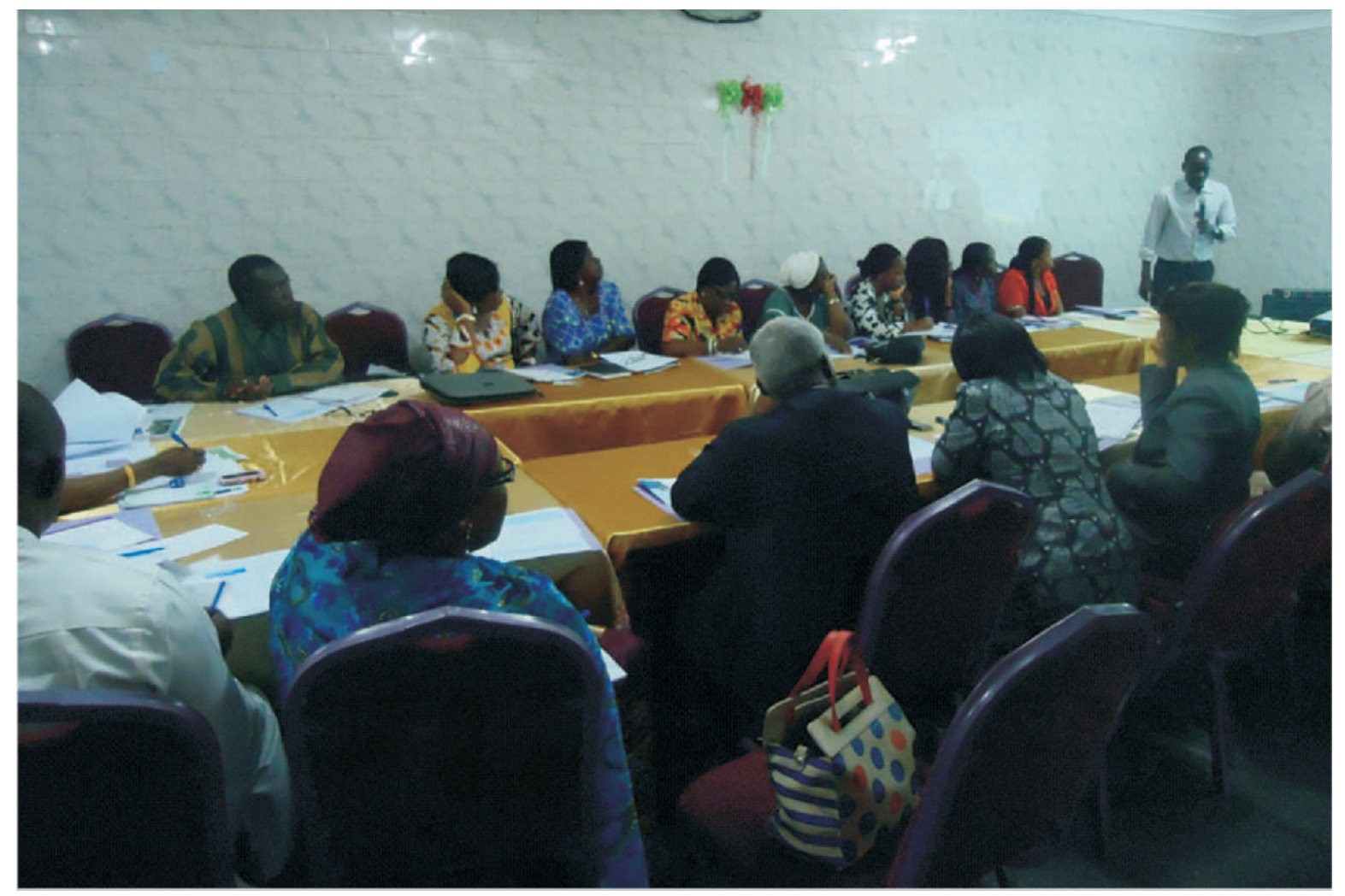

A cross-section of the participants 


\section{ADDRESSING PREVAILING MISCONCEPTIONS}

Participants reviewed several important misconceptions identified by the Population Council research regarding EC, such as: EC increases the risk of pregnancy; EC increases promiscuity among users; EC promotes contraceptive risk-taking behaviors; EC decreases use of condom and other methods of birth control and, invariably, increases the risk of transmission of STIs; EC is an abortifacient, and EC is not as protective as being advocated. Indeed, a youth advocate and mentor testified that many young girls affiliated to her organization still prefer harsh unproven traditional methods of avoiding a pregnancy such as salt solution, potash, and alum to EC. Further complicating these misconceptions is the availability in the market of counterfeit EC products and other family planning (FP) methods. While some of these methods are not ECs in the first place, the existence of counterfeit commodities affects EC uptake as well.

'What has clearly emerged is that ECs are being incorrectly defined and misclassified as one more addition to the growing list of abortifacients'

To support the demystification of EC and promote accurate information, participants agreed upon the following content for key messages to policy makers, program managers and clients:

ECPs are safe: Participants agreed that ECPs are indeed safe and, as the longitudinal study of Levonorgestrel has confirmed, they are well-tolerated and tend to leave the body quickly, thus dispelling the long-held misperception that EC increases vulnerability to addiction, toxicity, ectopic pregnancy, increased cancer risks and infertility.

EC is not an abortifacient: Another interesting point of agreement among participants was that EC should be set aside from the category of abortificient drugs, in that EC (whether ECPs or an IUD insertion after unprotected sex) is adopted by women immediately and only within five days after unprotected sex when pregnancy is unlikely to be established, and abortion out of the question. In other words, it is taken before fertilization occurs, which effectively eliminates the chances of associating it with abortion.

Legality of ECPs: Consensus was also reached at the dialogue that ECPs are legal in Nigeria although they are not yet included on the country's Essential Drugs List (EDL). There was a clarion call from the forum to hasten the incorporation of EC on the EDL to enable appropriate public budgetary provision for its purchase and distribution. More importantly, the dialogue recognized the potential in EC to offer women a second chance to prevent pregnancy when a regular method fails (e.g. condom breaks), they inadvertently skip their daily contraceptive pills, no method is used, or when exposed to sexual violence. Participants committed to integrating this vital information in routine family planning messages in the country. 


\section{STIMULATING DEMAND AND UPTAKE}

The forum then explored strategies on how to create demand and stimulate uptake in order to increase use of EC beyond the current estimated level of 2 million doses per annum. Participants identified several factors responsible for the initial expansion to this current level, namely: the massive launch of ECs by social marketers to generate awareness for providers and users in major Nigerian cities; the training of public and private sector providers to increase their understanding of the use of the product and to eliminate misconceptions; targeted promotion around critical user-groups, such as girls in tertiary institutions; leveraging existing family planning (FP) and reproductive health $(\mathrm{RH})$ programs to drive EC access and availability; use of private sector pharmaceutical distribution outlets; and, promoting sustainability through the adoption of an innovative cost recovery strategy and the provision of Pregnon, a subsidized brand that expanded consumer options.

It was unanimously agreed that 2 million doses of EC pills per annum is far below what is needed for a country with a teenage population of around 60 million.

To build on these early lessons and strategies, the forum called for renewed efforts to expand EC demand and uptake through the following measures:

Over-the-counter purchase: The forum was unanimous regarding the safety and appropriate provision of ECPs for over-the-counter (OTC) purchase and use by teenagers and older women without monitoring from a health provider. OTC access is critical because ECPs are more effective the sooner they are administered following exposure. A requirement for a prescription entails two trips: first to a clinic to get the prescription and second, to a pharmacist. This creates unnecessary obstacles and significantly impinges on the 'safety window.' This is the case even more so in rural dwellings that lack clinics and/or access to prompt transport services.

Service provider updates: Participants further observed that service providers are critical to improvement in uptake of ECs and need to be continuously trained using innovative strategies and materials, such as the Patent Medicine Vendors' (PMVs) Training Manual developed by SFH, which is regularly updated. The contents of the manual, which include FP counseling and referrals was developed under a public-private partnership. Part of the training approach, as suggested by the forum, should include leveraging concurrent meetings and conferences of relevant professional bodies to present current information on best practices around EC, because they are important messengers of this information to users. 
Interpersonal communication agents' orientation: The majority of participants proposed orientation and counseling training for Inter-Personal Communication (IPC) Agents, as one way to spread accurate information about EC. Interpersonal communication agents in rural areas are often beyond the reach of contemporary advocacy efforts. Using a dedicated team of pharmacists to undertake one-on-one training of providers on EC nationwide and creating sales teams to complement these efforts would further make current knowledge of EC available to both providers and clients in difficult and hard-to-reach locations. There remains a great need for dissemination of accurate and culturally appropriate information on EC to clients especially young women.

"Time should be spent to give information to the clients because it is the information you give to the people at the community that makes the difference. When young people get the right information, not necessarily about abortion, they will be able to share it among themselves. This is what should be considered very important to us" - Youth Peer Health Educator

EC in private sector outlets: Participants proposed boosting availability of EC in outlets similar to those being used to distribute condoms, supporting a key role for the private sector, in addition to the current public-private partnership.

Total market approach: The UNFPA representative affirmed that EC is one of the 13 life-saving commodities contained in the UN Commission Report. UNFPA traditionally supports the public sector in the procurement of family planning commodities but believes that ECs can be made more widely available by taking a total market approach requiring collaboration between the public and private sectors. Since the 2013 NDHS is underway and is expected to provide more insights on where women obtain contraceptives, including EC, it would help to inform where best to concentrate access expansion efforts - public or private sector.

Assuring product quality: The issue regarding the quality of EC products has negatively affected and will continue to impact uptake. Therefore, additional efforts are required to procure ECs from the right sources since FP failure is an issue that touches on the lives of many women. Women who have found themselves with fake or substandard EC have been known to become more fatalistic about their chances of preventing unwanted pregnancy.

"As a community of practitioners, we need to understand the anxiety of a woman who envisages that she might get pregnant as a result of unprotected sexual intercourse" - National NGO Program Manager 
An innovative strategy to support quality assurance is SFH's roll-out of a mobile-phone authentication service with Postinor-2. Under the mobile phone authentication service scheme, when prospective users buy the product, they send an SMS, free of charge, to a particular number and receive confirmation about whether the product they are buying is the fake or authentic. Nonetheless, the forum stressed that since the private sector may not reach as many Nigerians with modern health services as the public sector, both sectors have to work together to expand access to EC for needy girls and women.

"We have all agreed here that most family planning needs are being catered for through the private sector because of the inadequacies of the public sector. For example, undue time-wasting in public sector may not be tolerated by a woman in medical emergency. so many would resort to care in private facilities. Therefore, the empowerment of the private sector for effective service delivery is a right step in the right direction" - NURHI representative

Strengthening the supply chain: Participants raised another important issue associated with stimulating higher EC uptake, namely, strengthening the supply chain for delivering ECs to the market. While actors in the public sector indicated willingness to undertake product procurement and distribution through its regular channels, private sector stakeholders equally underscored the need to use their established channels. In the final analysis, it was agreed that both channels could be effectively combined for greater outcome.

Increasing access to EC among rape victims: Participants also addressed the issue of EC use to protect rape victims against unwanted pregnancies. It was advocated that since rape victims' first port of call is sometimes the police station, they should have immediate access to ECPs at the police stations even before statements are obtained from them. In the rural areas, there may be a primary health care (PHC) center that could supply ECs to the station and monitor their use. Police stations should be willing to dispense the drug to rape victims since it does not cost them anything to do so; however training is needed, preferably for designated female police officers, on dispensing the drug and offering complementary counseling before investigating police officers 
take the necessary records and follow up. Basically, ECs can be administered at a cost that is affordable, if not free. Similarly, the same strategy could be applied to gas stations across the country, which could immensely boost EC products distribution, availability, monitoring, evaluation and reporting. Police involvement in dispensing ECs to rape victims can only be realized through policy change on the part of the Nigeria Police Force.

"I think that we have to take part of the advocacy to the police and complement it with public awareness creation, so that officers-incharge can be capacitated to also offer counseling and make the service available. This can be used as part of the broad strategy of mainstreaming gender and HIV/AIDS advocacy in the police service and establishing gender desks in police stations" - Advocacy Nigeria 
Factors affecting the scale up of EC were extensively explored by participants. They described EC as a 'low hanging fruit' that is difficult to pluck considering all the misperceptions and valueclarification issues still associated with them, especially among providers in the public sector. In Nigeria, scale-up is also being slowed down by a combination of factors such as inadequate public sector involvement in EC supply, large number of providers yet to be trained on eligibility criteria for EC, high transfer/attrition rates of trained providers and the high cost of EC products in the face of high level of poverty especially in the northern regions of the country.

To address scale up, the following approaches were discussed by participants:

Ensure provider training includes values clarification: Providers often do not request ECPs even when they are ordinarily available, and given the misperceptions that many have around EC, this issue has to be tackled through targeted sensitization and training. Indeed, values clarification around EC (and FP in general) among SRH/FP program managers and service providers repeatedly came up as key to EC expansion in Nigeria.

"We have heard of a Family Planning Coordinator who buries FP commodities and key health personnel who hide FP products in their toilets" INGO Senior Manager

Continue to engage the private sector: In order to achieve rapid scale-up, participants felt it may be necessary to work closely with the private sector because of its flexibility in operation. For instance, providers in the private sector work over the weekends and for much longer hours on weekdays. Accordingly, there is need to train and support them with the necessary materials and create community level awareness about EC.Another point of consensus was that there is always paucity of funds, and so scale-up may be difficult to achieve considering that the private sector relies on donor funding that is fast-shrinking, unlike the government that can make policies and back it up with funds. Therefore, private sector operators must think out of the box for funding strategies that will ensure the sustainability of product delivery at whatever level they operate.

Integrate EC into existing FP/RH portfolios: The forum noted that it will be of tremendous help to integrate EC into the FP or RH portfolios being implemented by various organizations rather than treating it as a stand-alone or special topic. Apart from accomplishing the common broad goal of preventing unwanted pregnancy, integrating EC into existing $\mathrm{FP} / \mathrm{RH}$ information and service delivery platforms and channels will be more cost-effective and yield programme synergies. It should, therefore, not be separated from the routine services, and if it is not available at any clinic, there should be referrals to where it is available. There needs to be specific promotion (across and 
by all FP/SRH programs) of the notion that if a woman has unprotected sex, she can still avail herself of EC to prevent unwanted pregnancy. Such a messaging push will be quite timely now that Nigeria appears to be seriously looking at expanding youth-friendly RH services, and more donor agencies are re-visiting the issue of youth-friendly services. The country needs to be strategic about ensuring that EC is not put aside but is part of the comprehensive FP messaging and services especially when it comes to youth-friendly $\mathrm{RH}$ programs. 


\section{STRENGTHENING POLICY SUPPORT}

The participants agreed that an enabling policy environment is thus needed to give momentum to expansion of EC uptake in Nigeria and proposed the following:

Expand the dialogue to all levels of government: The need to expand discussion of the policy environment beyond the role of the federal government $(F G)$ was strongly recommended given that health policy-making and translation occurs across the three (3) tiers of government federal/national, state and local. It is also essential to consider the means to increase legislative support since the EC study revealed lack of proper knowledge and information around EC issues amongst both legislators and public sector officials.

In view of the foregoing, an important part of creating a suitable policy environment for EC is to ensure disseminated information is accessible and digestible to key policy actors and decisionmakers across the three tiers of government and the legislative, judicial and executive arms. This information needs to get to them in a way that they can understand and easily act upon given how very busy and crowded their agendas are.

Involve professional organizations: In addition, professional groups such as the Nigeria Medical Association (NMA), Pharmaceutical Society of Nigeria (PSN) and the Society of Obstetricians and Gynecologists of Nigeria (SOGON) and others, who can serve as either facilitators or stumbling blocks, should be engaged because they are also policymakers and influencers in their own right. For instance, recently in Ibadan, the PSN went about closing down shops that were selling ECPs, particularly Postinor 2, on the erroneous assumption that PMVs are not authorized to dispense EC pills. They obviously did not understand nor realize that Postinor 2 has now been upgraded to an over-the-counter (OTC) drug.

ECs on the Essential Drugs List: A major policy action repeatedly put on the table was how to build on the value of the existing training manuals and protocols on EC by getting the product listed on the Essential Drugs List (EDL) in Nigeria. Enabling laws are required at each specific level of policy to address the obvious issue of including ECs in the EDL. This should go hand-in-hand with the effort to materialize the new monetary pledge (additional \$8.35 million per year over 2013-2016) for expansion of access to FP in Nigeria by the President of Nigeria at the July 2012 London Summit on FP. There is the need to use available manuals to train providers and government officials at every level around $\mathrm{FP} / \mathrm{RH}$, and ECPs need to be central to these efforts.

Product quality assurance: Quality assurance and elimination of fake drugs is a major policy issue that the National Agency for Foods, Drugs Administration and Control (NAFDAC) has already initiated and working intensely to achieve. But attention was frequently called at the forum to the fact there are several fake EC pills on the Nigerian market which implies that actual demand for 
ECPs is far higher than the 2 million that SFH currently distributes annually. Though so many cases of counterfeit products have been reported to NAFDAC, the situation remains quite worrisome. Participants recommended continued and intensive advocacy with NAFDAC to improve the situation.

Engage local governments: Another forward-moving step noted by the forum would be for local governments to be empowered to rise up to their responsibilities of managing the PHCs under their jurisdiction, to have $\mathrm{RH}$ budget lines in their annual budgets and to train their health care personnel on RH - and EC - related issues. At present, they are not aware of the role of ECs and what they can do to support increased access; therefore, intensive advocacy is required.

Adolescents: On how best to speedily address the EC needs of adolescents, a widely expressed view was that since EC is captured in the National Family Planning Service Curriculum, ensuring that the product is included in Nigeria's EDL, and designated as a product that must be part of the services offered by a clinic to be considered youth-friendly is imperative. The forum, therefore, strongly urged participants from the Federal Ministry of Health to fully take this on board as part of the ministry's ongoing effort to develop the national minimum standard for youth-friendly $\mathrm{RH}$ services.

Brand marketing: It was also of great interest when participants learned that the subsidized EC product, Pregnon, is not as fast-selling as the more expensive product, Postinor-2, implying that affordability and brand loyalty were germane to EC uptake. Clearly, people are used to Postinor 2 and are ready to pay a premium to get that trusted medicine. It also underscores the value of promoting a unique and dedicated product that is protected against counterfeiting. 


\section{NEXT STEPS}

An immediate goal will be to ensure that ECPs such as Postinor-2 and Pregnon are included on Nigeria's EDL. Using this 'Day of Dialogue' as a momentum-gathering event, stakeholders promised to join forces together in pursuing this goal. Participants suggested borrowing a page from the ongoing national polio eradication effort which uses champions in communities or organizations to drive the cause in their respective settings, rural and urban. Empowering the champions of existing FP programs with sufficient EC knowledge will be of immense help, especially when they are counseling clients on methods and trying to help communities to take actions on major $\mathrm{FP} / \mathrm{RH}$ issues.

There is strong and compelling scientific evidence about the safety of ECPs which can firmly counter prevailing misperceptions associated with it. Therefore, there is a need to urgently tackle these misconceptions by working to understand and resolve the reasons for resistance against EC uptake. It is also pertinent to understand why potential clients are not offered EC as an option and the reasons behind portraying EC as abortificient and for associating it with the promotion of promiscuity in women, so that strategies can better address these problems.

Equally of immense importance is the need to find a way to more effectively disseminate information on EC and other $\mathrm{RH}$ issues. To achieve this requires the simplification of the information and making it easily available to the larger public through massive and persistent advocacy and sensitization.

"People already know enough about HIV, how it is acquired, how it leads to AIDS and how it is managed. But we have not been able to achieve such high level of knowledge and awareness around FP" - Head of an INGO

At every meeting, people still raise a lot of questions regarding FP (including EC) that ought to have been long settled. The growing donor attention to FP provides a new opportunity for the FP/RH field in Nigeria to make the kind of positive impact that the HIV/AIDS field has been able to achieve. What is immediately required is for the $\mathrm{FP} / \mathrm{RH}$ community of practice to sustain and increase its community mobilization, public education, service delivery and policy advocacy efforts for the expansion of access to FP, including EC, for all categories of women in Nigeria. 


\section{Conclusion}

This 'dialogue' is the first of its kind around emergency contraception in Nigeria. It brought participants from diverse backgrounds, and presented the current information on emergency contraception from the perspectives of the service providers and policy-makers, and thus, set the stage for a constructive discourse. Various commitments were made ranging from building and sustaining advocacy efforts, increasing collaboration among relevant partners, mentoring and capacity building for service providers, and improved monitoring of program/service delivery. However, this new-found commitment for EC will require regular and on-going meetings, information sharing and collaborative actions in the months and years ahead if the set commitments are to be fulfilled. 


\section{APPENDIX I}

The Agenda for the 'Day of Dialogue'

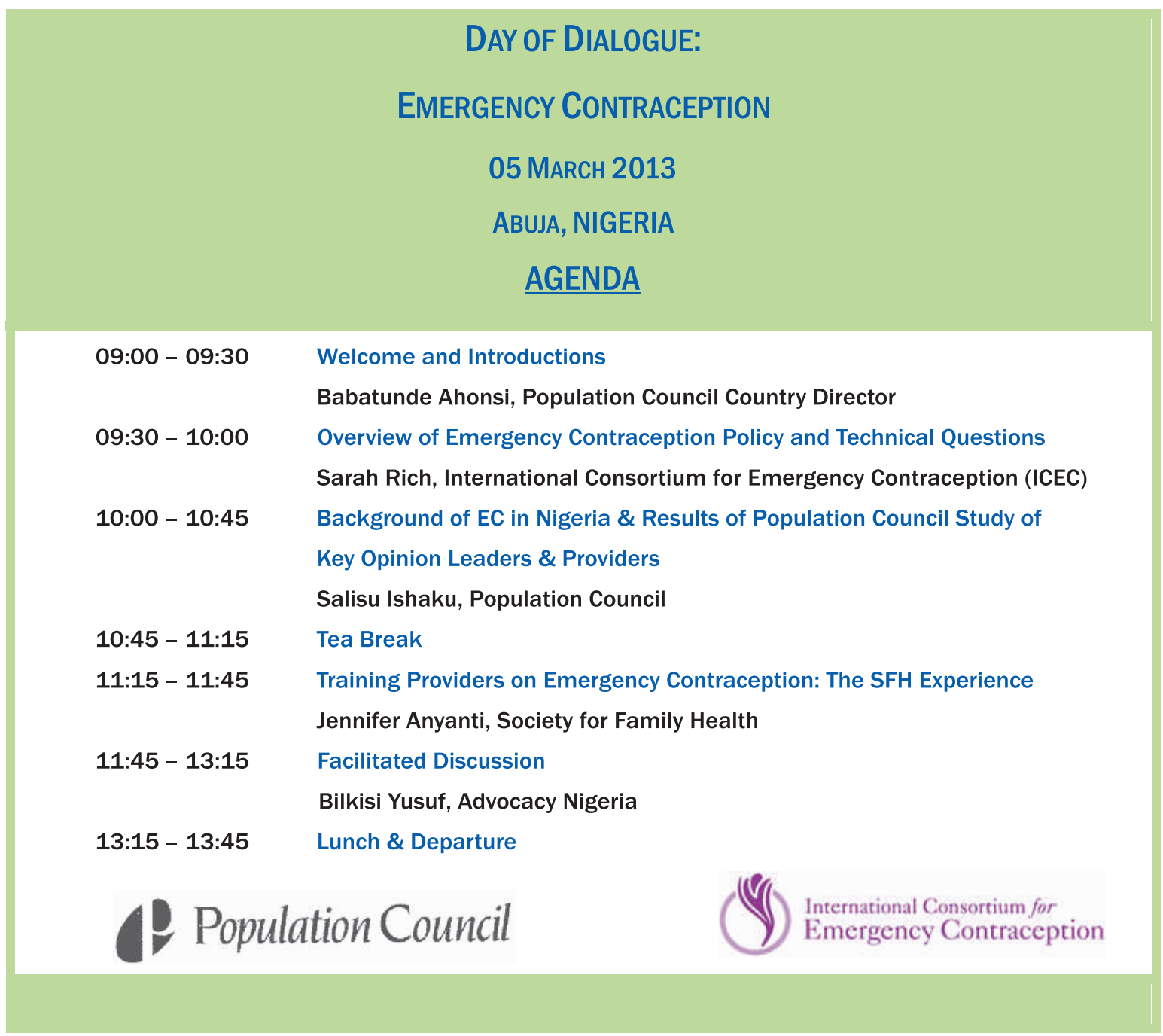




\section{APPENDIX II}

\section{List of participants}

\section{Jennifer Anyanti}

Director, Technical Services

Society for Family Health, Abuja

Email: janyanti@sfhnigeria.org

\section{Obinna Nwogu}

Fund Manager

Society for Family Health, Abuja

Email: onwogu@sfhnigeria.org

\section{Augustina 0. Salami}

Program Coordinator

Education as A Vaccine, Abuja

Email: tina.saami@gmail.com

\section{Oyemina Rita}

Vice President

Nigeria Association of Patent and

Proprietary Medicine Dealers, Abuja

\section{Sa'adatu Sule}

Technical Advisor for Nigeria, Making It Happen Programme Liverpool School of Tropical Medicine Email: saasule@yahoo.com

\section{Ladipo}

President /Chief Executive Officer Association for Reproductive and Family Health, Abuja

Email: oaladipo@yahoo.co.uk

\section{Hajiya Bilkisu Yusuf}

Executive Director

Advocacy Nigeria/Family Planning

Action Group, Abuja

Email: bilkisuy@yahoo.com

\section{Farouk Jega}

Country Representative

Pathfinder International Nigeria

Abuja

Email: fjega@pathfinder.org

\section{Bose Adeniran}

Head of Reproductive Health Division

Federal Ministry of Health, Abuja

Email: boseade4000@yahoo.com

\section{Sylvia Ekponimo}

Team Leader

Education as A Vaccine, Abuja

Email: sylviae@evanigeria.org

\section{Charity Ibeawuchi}

Advocacy Advisor

Nigerian Urban Reproductive Health

Initiative, Abuja

Email: cibeawuchi@nurhi.org

\section{Celina Johnson}

Public-Private Sector Advisor

Nigerian Urban Reproductive Health Initiative, Abuja

Email: cjohnson@nurhi.org

Wale Adedeji

Chief Operating Officer

Society for Family Health, Abuja

Email: wadedeji@sfhnigeria.org

\section{Tali G. Butkap}

Deputy Director

Public Health and Human Services

Secretariat

Federal Capital Territory, Abuja

Email: Drtali2001@yahoo.com

\section{Kehinde Oshinowo}

Director, Programs

Association for Reproductive and

Family Health, Abuja

Email: Kosmowo2@yahoo.com

\section{Cynthia Mmaduka}

Monitoring and Evaluation Officer

Education as A Vaccine

Abuja

Email: Cynthiaonyekaeli30@yahoo.com

\section{Obi Oluigbo}

Chief Technical Officer

Society for Family Health Abuja

Email: ooluigbo@sfhnigeria.org 
Mariam Momoh

Family Planning Coordinator

Federal Capital Territory, Abuja

Email: tomimariam@yahoo.com

\section{Olanike Adedeji}

National Program Officer

Reproductive Health Commodity Supply

United Nations Population Fund, Abuja

Email: oadedeji@unfpa.org

\section{Nasa Eke}

Fund Raiser

Education as A Vaccine

Email: leonaeke@gmail.com

\section{Orji Ejike}

Country Director

IPAS- Nigeria

Abuja

Email: dreoji@yahoo.com

\section{Sarah Rich}

International Consortium for Emergency

Contraception, New York

Email: srich@familycareintl.org

\section{Babatunde Ahonsi}

Country Director

Population Council, Abuja.

Email: bahonsi@popcouncil.org

\section{Salisu Ishaku}

Senior Program Manager

Reproductive Health

Population Council, Abuja.

Email: sishaku@popcouncil.org

\section{Gloria Adoyi}

Program Officer

Reproductive Health

Population Council, Abuja.

Email: gadoyi@popcouncil.org

\section{Godwin Unumeri}

Consultant Centre for Citizens with

Disabilities Lagos

Email: unumerig@yahoo.com

\section{Joel Odoh}

President

Nigeria Association of Patent and

Proprietary Medicine Dealers, Abuja

\section{Odoh Theophilus}

Secretary General

Nigeria Association of Patent and

Proprietary Medicine Dealers, Abuja

\section{Akinkunmi Agnes}

Program Officer

Federal Ministry of Health

Abuja

Email:Yemisiakinkunmi2000@yahoo.com

\section{Wophill Rotmwa}

Program Officer, Advocacy, Policies and

Campaign

Education as A Vaccine

Email: Rotwop286@gmail.com

\section{Temitope Bombata}

Chief Nursing Officer

Federal Ministry of Health

Abuja

Email: Taboms1963@yahoo.com

\section{Abdulmalik Abdulazeez}

Program Officer

Education as A Vaccine, Abuja

Email: bushgame2003@yahoo.com

\section{Erega Bangha}

Monitoring and Evaluation Officer

Public Health Department

Federal Capital AIDS \& STIs Control

Program

Abuja

Email:erecaly@yahoo.com 


\section{REFERENCES}

1. Ahonsi B, Ishaku S, Araoyinbo I, and Oginni A, (2012), Providers' and Key Opinion Leaders' Attitudes, Beliefs, and Practices Regarding Emergency Contraception in Nigeria: Key Findings, Program Brief, New York, Population Council.

2. Brady M. and McGrory E. (2007), Insights and Evidence from Product Introduction: Lessons for Microbicides, Day of Dialogue Series, New York, Population Council.

3. National Population Commission (NPC) and ICF Macro (2009) Nigeria Demographic and Health Survey 2008. Abuja, Nigeria: NPC and ICF Macro. 


\section{(1) Population Council}

Nigeria

16 Mafemi Crescent

Off Solomon Lar Way Utako District

Abuja

www.popcouncil.org 